\title{
Defect Assessment Using Conformable Array Data
}

\author{
Quarterly Report \\ 1 October 2002 to 31 January 2003
}

\author{
Prepared by \\ Alfred E. Crouch \\ Applied Physics Division \\ Southwest Research Institute ${ }^{\circledR}$ \\ 6220 Culebra Road \\ San Antonio, TX 78238
}

January, 2003

DOE Contract No. DE-FC26-02NT41644

SwRI® Project No. 14.06239

\section{Prepared for}

National Energy Technology Laboratory

3610 Collins Ferry Road

Morgantown, WV 26507 


\section{Disclaimer}

This report was prepared as an account of work sponsored by an agency of the United States Government. Neither the United States Government nor any agency thereof, nor any of their employees, makes any warranty, express or implied, or assumes any legal liability or responsibility for the accuracy, completeness or usefulness of any information, apparatus, product or process disclosed, or represents that its use would not infringe privately owned rights. Reference herein to any specific commercial product, process or service by trade name, trade mark or manufacturer or otherwise does not necessarily constitute or imply its endorsement, recommendation or favoring by the United States Government or any agency thereof. The views and opinions of authors expressed herein do not necessarily state or reflect those of the United States Government or any agency thereof. 


\section{Abstract}

This first quarterly report of the project presents the activity and conclusions reached to date. Specifically, several of the design parameters of the field eddy current array have been determined and the overall approach to data collection and analysis selected. A kick-off meeting was held at the Clock Spring Company offices, where the project status was presented to the NETL Project Officer. 


\section{Table of Contents}

Introduction $\quad 5$

Experimental 5

Results and Discussion 5

Conclusion $\quad 8$

References $\quad 8$ 


\section{Introduction}

This first quarterly report is very brief because much of the time of the first quarter was spent in getting the Clock Spring Company subcontract in place. Most of the major decisions on design parameters have been made, however, and work is now progressing to implement them. A kick-off meeting was held on January 13 at the Clock Spring office in Houston at which time the project progress and plans were presented and discussed.

\section{Experimental Work}

The work in this project will build on the success of the previous project which showed feasibility for use of a conformable array. The feasibility array is shown in Figure 1.

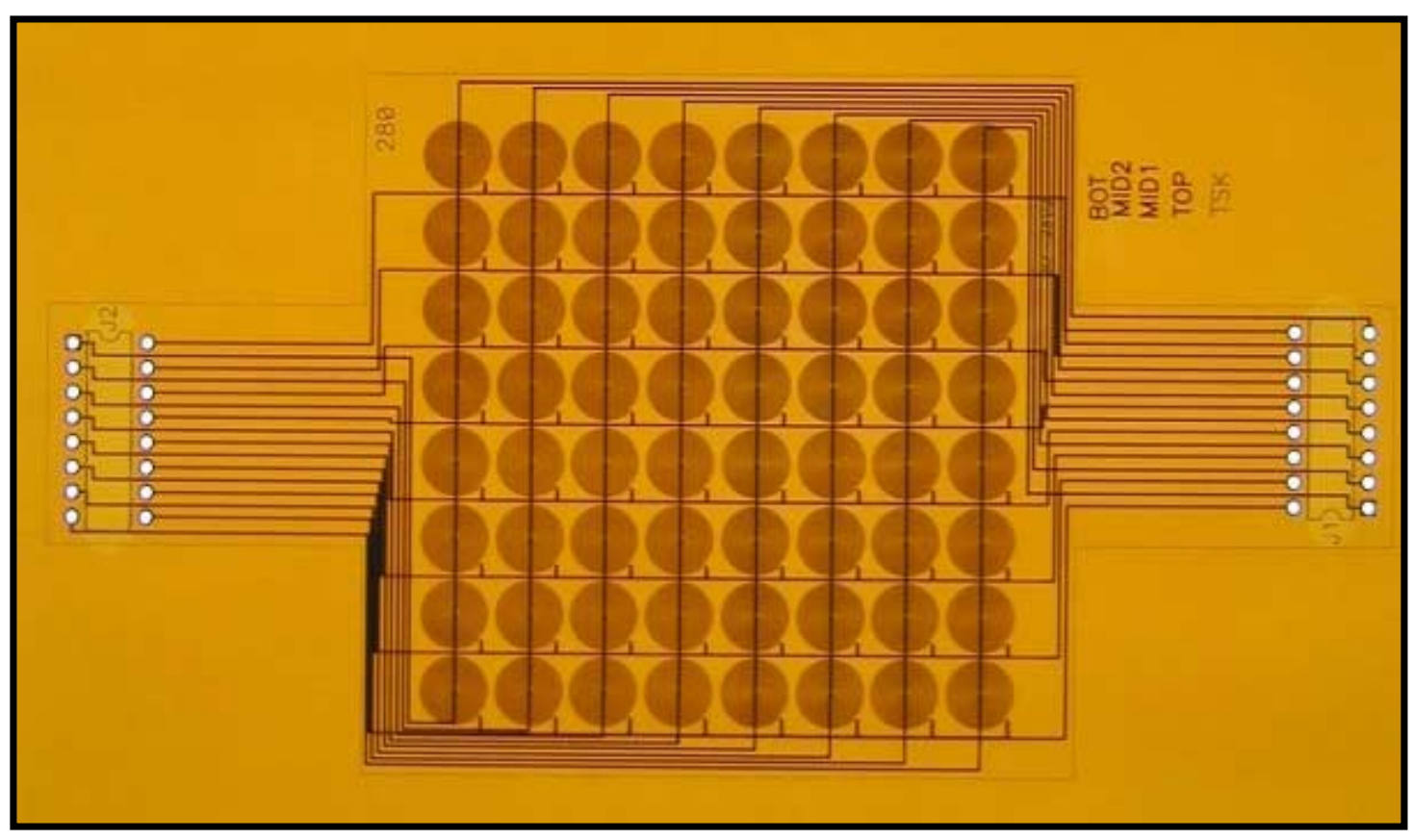

Figure 1. Feasibility array showing 64 sensing coils and two contact patterns for mounting dual-in-line sockets.

The connecting scheme used for the feasibility array was a matrix connection that brought out single lines for rows and columns. Because of potential crosstalk problems, a different connection approach will be used for the field array. The field array will have isolated single lines for each coil.

\section{Results and Discussion}

The field array will have coils that are approximately $10 \mathrm{~mm}$ in diameter. The array board will contain a central sensing area of approximately 12 by 12 coils. 
On the same board will be mounted circuit components to interface with the sensing array and produce data that is stored and processed. Figure 2 shows an artist concept of the field array.

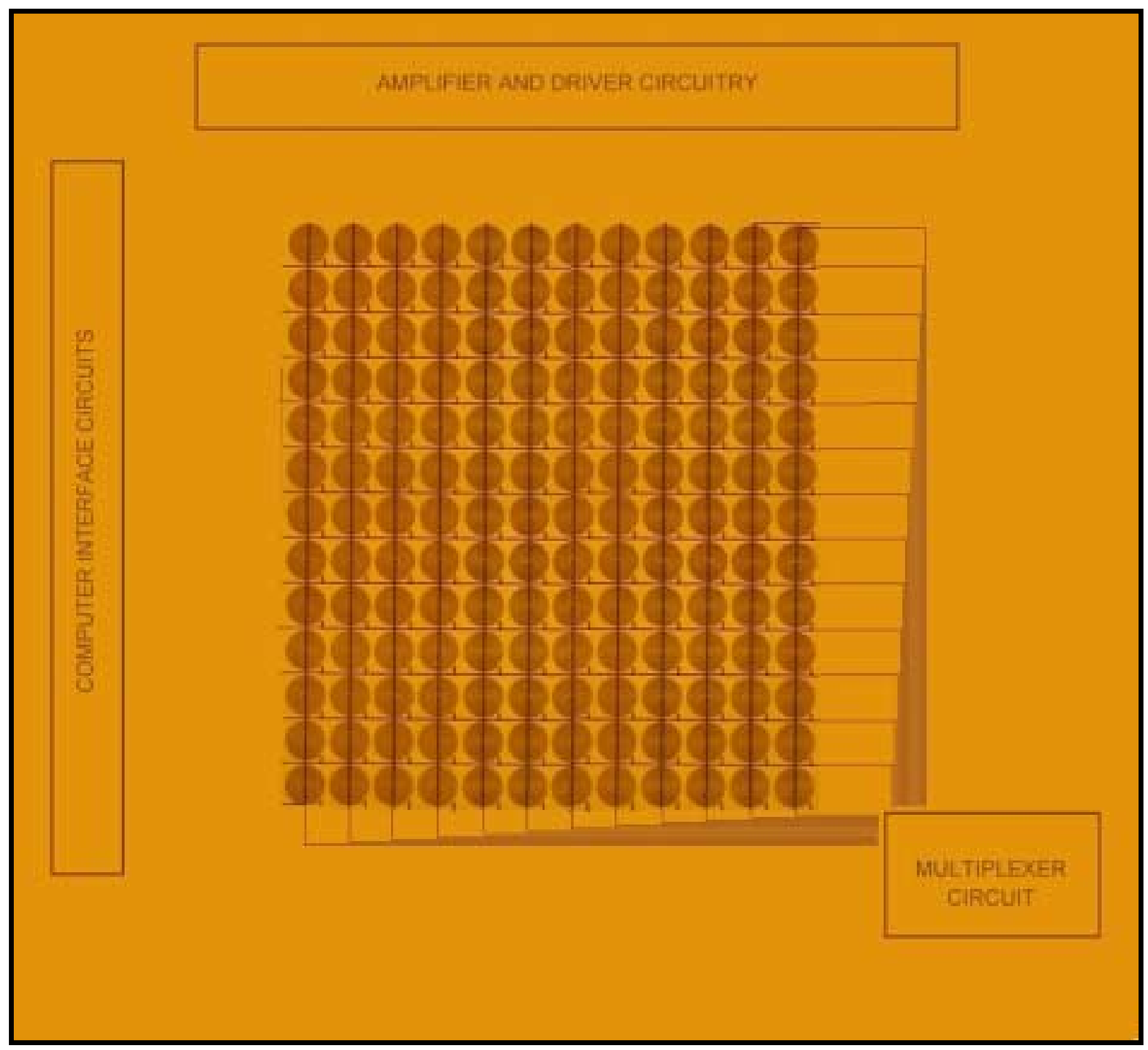

Figure 2. Proposed field array showing installation of basic circuit elements on the sensor array substrate.

It is anticipated that all functions necessary to produce data for computer analysis will be implemented on the conformable array board. These functions include multiplexing the multiple coil signals, providing drive current and amplifying the secondary signals. Appropriate filtering and analog to digital conversion may also reside on this board. 
The corroded area will be mapped by successive positions of the array board. The corrosion data file will be built up by merging the separate maps. Index marks will be provided to facilitate the merging. These index marks may be placed directly on the pipe surface or onto a thin sub-sheet of circuit board material placed underneath the coil array.

Application of the array in the field will be done using laboratory grade instruments. The project budget does not allow design and fabrication of field grade instrumentation.

Data analysis will be carried out using a notebook computer. The operator will be able to "box " pit signals on the color map and have B31G or RSTRENG-type analysis applied to the signals inside the box. Figure 3 shows a sample map from the feasibility array with two candidate boxes drawn in.

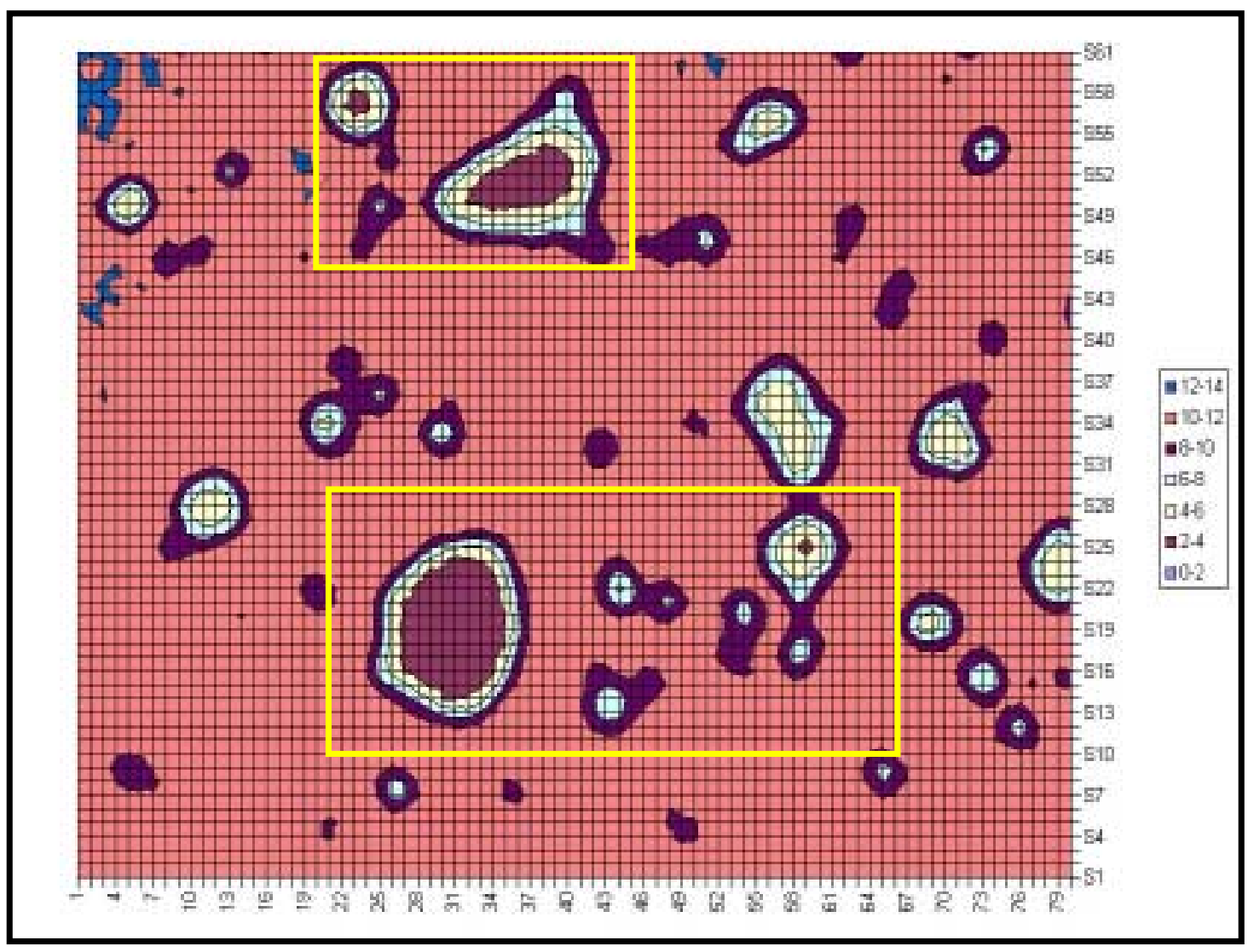

Figure 3. Sample data color map showing operator-selected analysis boxes.

Attempts will be made to automate the boxing process if possible so that the computer can give the operator guidance of which signals are most important. 


\section{Conclusion}

The project activities are consistent with those laid out in the proposal. The system is still planned to be as shown in the artist concept presented below.

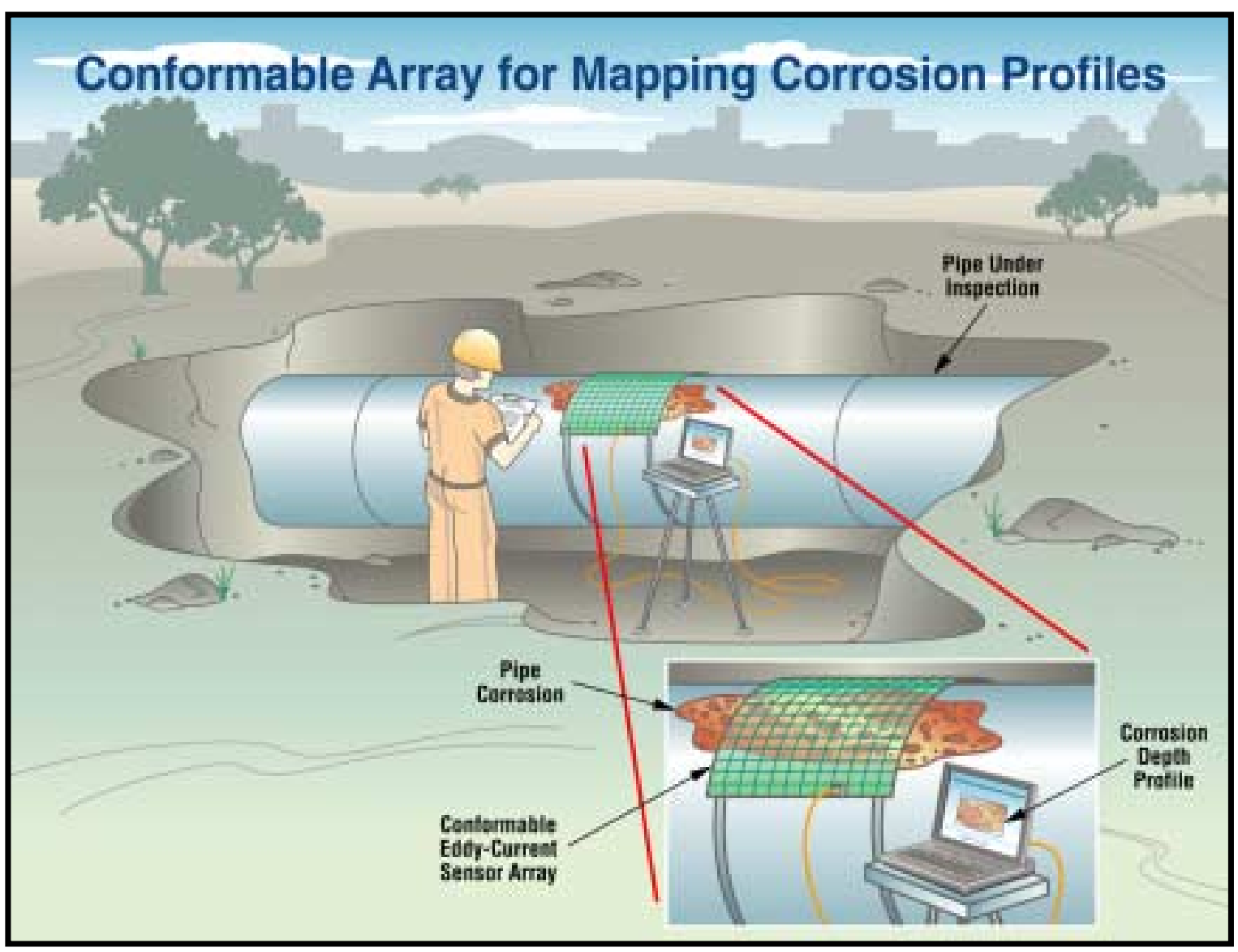

The next quarter will see the initial layout of the array board and the specification of the data acquisition and analysis hardware.

\section{References}

"Conformable Array for Mapping Corrosion Profiles", Final Report , August 21, 2001 - November 21, 2002. DOE Contract No. DE-FC26-01NT41153, November 2002. 